\title{
Cryptosporidiosis among Hemodialysis Patients in Jordan: First Preliminary Screening Surveillance
}

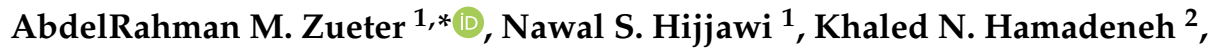 \\ Maysa M. Al-Sheyab ${ }^{3}$ and Amal M. Hatamleh ${ }^{4}$ \\ 1 Department of Medical Laboratory Sciences, The Hashemite University, Zarqa 13133, Jordan; \\ nhijjawi@hu.edu.jo \\ 2 Nephrology Department, King Hussein Medical Center, Amman 11118, Jordan; KhaledH@rms.jo \\ 3 Medical Microbiology Department, Prince Rashed Bin AL-Hassan Military Hospital, Irbid 21110, Jordan; \\ Meso@rms.jo \\ 4 Medical Hematology Department, Prince Rashed Bin AL-Hassan Military Hospital, Irbid 21110, Jordan; \\ AmalMufade@rms.jo \\ * Correspondence: abdelr@hu.edu.jo; Tel.: +962-798190685
}

Received: 28 September 2019; Accepted: 15 October 2019; Published: 18 October 2019

\begin{abstract}
Few studies have reported the incidence of cryptosporidiosis among hemodialysis patients worldwide. Currently many molecular and immunological assays have been developed for the sensitive diagnosis of cryptosporidiosis, but still, the microscopic detection of the parasitic infective stage (oocysts) in stool specimens using modified acid stain is regarded as a reliable sensitive technique which is widely used in many clinical labs. In the present study, a total of 133 stool samples were collected from hemodialysis patients and were screened for Cryptosporidium oocyst using formalin-ether concentration and modified acid-fast staining technique. Clinical and demographic data were also collected and analyzed. Cryptosporidium oocysts were recovered in 15/133 (11\%) of the investigated hemodialysis patients. The age of patients ranged from 25 to 80 years (mean: $57.84 \pm 12.22)$. Most of the Cryptosporidium-positive cases were recovered from males $(73.7 \%)$ residing in rural villages in Irbid city $(86.6 \%)$. The most repeatedly reported symptoms in the Cryptosporidium-positive patients were gastrointestinal symptoms, including diarrhea (15\%), nausea (24\%), abdominal pain (23\%) and bloating (17\%), in addition to general fatigue (32\%) and weight loss (19\%). No statistically significant associations for certain clinical symptoms or risk factors were found. The present study is the first preliminary study in Jordan that provided a brief screening for the incidence of cryptosporidiosis among hemodialysis patients.
\end{abstract}

Keywords: cryptosporidiosis; hemodialysis; Jordan; acid-fast stain

\section{Introduction}

Cryptosporidium species is an important intracellular apicomplexan protozoan parasite that infects a wide range of hosts including humans, domestic and wild animals worldwide [1,2]. Cryptosporidium has been ranked as the sixth most important food-borne parasite worldwide [3].

Human cryptosporidiosis was first observed in 1976, and it was later recognized as a major cause of chronic diarrhea in AIDS patients and children and was responsible for many zoonotic and waterborne diarrheal outbreaks worldwide [4]. Furthermore, awareness of cryptosporidiosis was growing globally, especially among malnourished children and reported to be a cause for premature death in low-resource settings [5-7].

Cryptosporidium life cycle starts upon the ingestion of the oocysts that shed with the infected host's stool and can be transmitted to new hosts via the fecal-oral route [8]. Cryptosporidiosis is 
usually self-resolving in immunocompetent individuals; however, it might lead to life-threatening complications in immunocompromised patients [2]. Cryptosporidiosis causes acute diarrhea with elevated morbidity and mortality in children, immunocompromised patients, such as AIDS patients, cancer patients and hemodialysis patients [3,9-11].

Microscopy using acid-fast staining, with or without stool concentration, is the most widely used screening technique globally for the diagnosis of Cryptosporidium since it is cheap and accessible especially in rural settings and shows high sensitivity in comparison with other parasitological, immunological and even molecular techniques [2,10,12].

Cryptosporidium oocysts were investigated in several studies either alone or along with other intestinal parasites among different population groups [13-16], as well as, in the environment [17-19] and domestic animals $[20,21]$. In Jordan, studies on Cryptosporidium were conducted on normal and immunocompromised patients among different age groups [10,12,22-25].

To increase the awareness toward Cryptosporidium infection in Jordan, hemodialysis patients were included in this report. Hemodialysis patients usually suffer from frequent episodes of diarrhea and various gastrointestinal symptoms, and thus suspected to be at an increased probability of shedding a hidden cryptosporidiosis which might be unpredicted by the treating physician since the infection is neglected among these patients and has never been investigated before [10].

Additionally, hemodialysis patients are known to experience immune suppression, so they are at high risk of acquiring cryptosporidiosis more than any other patient [26]. Moreover, hemodialysis patients usually suffer from chronic renal failure since they have defects in kidney functions that lead to retention of uremic toxins in the blood. Uremic toxins interfere with cellular and humoral immunity functions leading to increased individual susceptibility to infections [26]. Uremic toxins-associated immune deficiency is considered as the second most significant factor responsible for the high morbidity and mortality among chronic renal failure patients after cardiovascular diseases [27].

Parasitic infections are one of the significant causes of morbidity and mortality in hemodialysis patients [26]. Intestinal parasites, in particular, Entamoeba histolytica, Giardia lamblia, opportunistic Cryptosporidium species and Strongyloides stercoralis are prevalent in developing countries, especially among chronic kidney disease patients who are undergoing hemodialysis [26,28].

A few studies performed in several countries had reported the incidence of cryptosporidiosis among hemodialysis patients and had applied mainly modified acid-fast staining microscopy as the screening diagnostic method of choice $[26,29,30]$. Therefore, the main aim of the present study was to provide a preliminary investigation for the incidence of cryptosporidiosis among hemodialysis patients in Jordan using simple modified acid-fast staining.

\section{Materials and Methods}

\subsection{Patients Recruitment and Ethical Approval}

This study was done after obtaining ethical approval from the institutional review board (IRB) at Hashemite University (number 16/11/1800857). Informed consent was obtained from all participants (hemodialysis patients and normal individuals who served as a negative control).

In the present study, a total of 133 fresh stool samples were collected from hemodialysis patients at King Hussein Medical Center in Amman and Prince Rashed Bin AL-Hassan Military Hospital, Irbid from April to October 2018. At the same time, 50 fresh stool samples were collected from healthy individuals from the same collection places to serve as a negative control.

\subsection{Demographic and Clinical Data Collection}

Recruited hemodialysis patients in this study belong predominantly to low-income communities. All patients were orally consented to participate in this study by the staff nurse and they answered a standardized questionnaire concerning demographic data, such as sex, age, residency and symptoms related to intestinal manifestations such as diarrhea (having at least 3 loose stools a day), abdominal 
pain (diffuse pain in the abdominal cavity), stomach pain (cramps in the tummy), weight loss (decrease $>5 \%$ of body weight within 6 months), fatigue (sustained decrease in the strength), nausea or vomiting (frequent sensation or acting of forcible emptying of the stomach) and bloating (abnormal stomach swelling or feeling full). Data analysis was carried out using the SPSS software version 25 (SPSS, Chicago, IL, USA).

\subsection{Stool Samples Testing}

Collected stool samples were preserved in 10\% formalin and kept in a cool and dry place until examination. Stool samples were concentrated and stained by a modified acid-fast staining technique before being screened for Cryptosporidium oocysts, as described previously $[10,11]$. Briefly, stool samples were concentrated using formalin-ether method and a separate thin microscopic smear was prepared for each sample. The smears were then fixed with absolute methanol for 30 seconds. Thereafter, smears were stained with carbol fuchsin for 3 minutes, rinsed briefly with tap water, decolorized by $3 \%$ acid alcohol for 4 seconds and then counterstained with methylene blue for 1 minute. The stained dried slides were labeled and examined for the presence of Cryptosporidium oocysts at an oil immersion lens under a light microscope.

\section{Results}

Clinical and demographic data were recovered for 100 out of 133 patient's files and were reviewed. In the present study, the age of patients ranged from 25 to 80 years (mean: $57.84 \pm 12.22$ ) and more than two-thirds of them were males 72\% (72/100). Microscopic screening of the 133 stool specimens in the present study identified Cryptosporidium oocysts in 15 hemodialysis patients (11\%) and no oocysts were observed in any of the control samples (see Table 1).

Table 1. Positive cryptosporidiosis among gender.

\begin{tabular}{cccc}
\hline & \multicolumn{2}{c}{ Modified Acid-Fast Microscopy } & \\
\cline { 2 - 3 } Gender & Negative & Positive & Total \\
\hline Female & 24 & $4(26.3 \%)$ & 28 \\
Male & 61 & $11(72.7 \%)$ & 72 \\
\hline
\end{tabular}

During the present study, more than half of stool samples were collected from patients living in Irbid city in Northern Jordan, while the remaining samples were collected from residents in other cities of Jordan such as Amman, Al-Salt, Jerash, Madaba, and Zarqa. Thirteen out of fifteen (86.6\%) Cryptosporidium-positive patients came from rural villages in Irbid.

Most Cryptosporidium-positive hemodialysis patients were experiencing at least one of the investigated gastrointestinal symptoms, including diarrhea $15 \%$, nausea $24 \%$, abdominal pain $23 \%$ and bloating $17 \%$, in addition to general fatigue $32 \%$ and weight loss $19 \%$. However, no statistically significant ( $p$-value $>0.05$ ) association for certain clinical symptoms or risk factors was reported during the present study (data not shown).

\section{Discussion}

Hemodialysis patients are more susceptible to opportunistic parasitic infections since their immune response is impaired [26]. The incidence rate of cryptosporidiosis among hemodialysis patients is severely underestimated worldwide since few studies have been performed in different countries [31]. In Jordan, no studies to assess the prevalence of cryptosporidiosis among hemodialysis patients were performed. Regarding Cryptosporidium prevalence among patients with impaired immune response, only one single study was performed to assess the prevalence of cryptosporidiosis among pediatric oncology patients which reported a higher prevalence (14.4\%) compared to pediatric non-oncology children (5.1\%) [11]. The above-mentioned study had encouraged further investigations 
for cryptosporidiosis infection rates among targeted patients' groups such as hemodialysis patients who are exposed to episodes of immunosuppression.

In the present study, the prevalence of cryptosporidiosis among hemodialysis patients was $11 \%$ and the age of patients was ranged from 25 to 80 years (mean: $57.84 \pm 12.22$ ) with more positivity seen among males $72 \%(72 / 100)$. The percentages observed in this study harmonized with those obtained from similar studies worldwide [30-32] and with results obtained previously in Jordan from pediatric cancer patients $14.4 \%$ [10]. However, the prevalence of cryptosporidiosis in Jordan ranges from 4 to $19 \%$ and modified acid-fast staining microscopy was frequently used as the diagnostic method of choice $[10,12,24,33]$. Moreover, the prevalence of cryptosporidiosis in Jordan was investigated in many studies on different settings (elementary school children $4 \%$, in pediatric cancer patients $14.4 \%$, in preschool children $6.7 \%$, in patients with diarrhea living in rural areas $8 \%$ and in children $19 \%[10,24,25,33,34]$. Based on the literature, the incidence of hemodialysis in Jordan is common among male gender [35], which explains the increased cryptosporidiosis positivity among males in this study; 11 males versus 4 females (see Table 1).

More than half of the stool samples were collected from patients living in Irbid city in Northern Jordan and $86.6 \%$ of Cryptosporidium-positive patients came from rural villages in Irbid. This came in agreement with other conduced previous studies in Jordan which reported high incidence rates of cryptosporidiosis among populations of rural areas of Irbid city [12,22,25]. Several risk factors attributed to the increase in the cryptosporidiosis infection were in Northern Jordan, such as the use of underground water for drinking which is usually exposed for contamination from the sewage, contact with domestic animals, and eating unwashed vegetables [22,24,33]. Also, it was reported that the cryptosporidiosis rate in the rural population was higher than the urban population in the hemodialysis patients' group [11,26].

Gastrointestinal symptoms were seen in most Cryptosporidium-positive hemodialysis patients with neither predomination of certain symptoms nor statistically significant association for certain clinical symptoms or risk factors. In general, several studies reported similar demographical and clinical findings among hemodialysis patients in many countries [11,26,31,36]. Diversity in prevalence rates of cryptosporidiosis among hemodialysis patients is attributed to the prevalence of parasitic infection in the region of sampling, environmental, climatic and sanitary factors [26]. Table 2 summarizes recent updates regarding cryptosporidiosis prevalence among hemodialysis patients in different countries.

Table 2. Cryptosporidiosis among hemodialysis patients worldwide.

\begin{tabular}{|c|c|c|c|c|c|c|}
\hline Country & Study Interval & $\begin{array}{l}\text { Sample } \\
\text { Size }\end{array}$ & Prevalence & Risk Factors & Diagnostic Method & Ref \\
\hline Egypt & $\begin{array}{l}\text { Aug. 2014-Apr. } \\
2015\end{array}$ & 330 & $3 \%$ & $\begin{array}{l}\text { Residency, } \\
\text { hygiene, } \\
\text { education }\end{array}$ & $\begin{array}{l}\text { Concentration and } \\
\text { modified Ziehl-Neelsen } \\
\text { staining }\end{array}$ & [11] \\
\hline Egypt & Jan.-Dec. 2017 & 150 & $40 \%$ & $\begin{array}{l}\text { Contact with } \\
\text { domestic } \\
\text { animals }\end{array}$ & $\begin{array}{c}\text { Wet mount, } \\
\text { Concentration and } \\
\text { modified Ziehl-Neelsen } \\
\text { staining }\end{array}$ & [26] \\
\hline Brazil & Apr.-Sept. 1993 & 78 & $10 \%$ & Not reported & $\begin{array}{c}\text { Concentration and } \\
\text { modified Ziehl-Neelsen } \\
\text { staining }\end{array}$ & [32] \\
\hline Turkey & 2001 & 74 & $20 \%$ & Not reported & $\begin{array}{l}\text { Modified Ziehl-Neelsen } \\
\text { staining }\end{array}$ & [36] \\
\hline Iran & 2000-2001 & 104 & $11.5 \%$ & Diabetes & $\begin{array}{c}\text { Modified Ziehl-Neelsen } \\
\text { staining }\end{array}$ & [31] \\
\hline Brazil & $\begin{array}{l}\text { Apr. 2006-Sept. } \\
2007\end{array}$ & 86 & $4.7 \%$ & $\begin{array}{l}\text { Middle-age } \\
\text { group }\end{array}$ & $\begin{array}{l}\text { Kinyoun acid-fast } \\
\text { staining }\end{array}$ & [29] \\
\hline Iran & $\begin{array}{l}\text { May 2013-Jan. } \\
\quad 2014\end{array}$ & 78 & $11.5 \%$ & Residency & $\begin{array}{c}\text { Direct-smear, } \\
\text { formol-ether and } \\
\text { modified Ziehl-Neelsen } \\
\text { staining }\end{array}$ & [30] \\
\hline
\end{tabular}


Table 2. Cont.

\begin{tabular}{ccccccc}
\hline Country & Study Interval & $\begin{array}{c}\text { Sample } \\
\text { Size }\end{array}$ & Prevalence & Risk Factors & Diagnostic Method & Ref \\
\hline Iran & $1997-1999$ & 103 & $3.88 \%$ & $\begin{array}{c}\text { Duration of } \\
\text { hemodialysis }\end{array}$ & $\begin{array}{c}\text { Modified Ziehl-Neelsen } \\
\text { staining }\end{array}$ & [37] \\
\hline
\end{tabular}

\section{Conclusions}

This is the first preliminary study in Jordan that provided brief screening for the incidence of cryptosporidiosis in hemodialysis patients. More clinical and molecular epidemiological surveys should be conducted in Jordan on the immunodeficient hosts such as hemodialysis and cancer patients to provide a better understanding of Cryptosporidium prevalence, pathogenesis, and routes of transmission among this category of patients.

Author Contributions: A.M.Z. leaded the work, drafted the paper and did the laboratory work; N.S.H. shared paper drafting and provided logistic support; K.N.H. supervised sample collection at the hemodialysis ward; M.M.A.-S. and A.M.H. did sample collection and prepared samples for laboratory work.

Funding: This research received no external funding.

Acknowledgments: We would like to thank Rania Mherat, Khaleda Abualkhael and Razan Rahmoun for their support in research logistics. In addition, we appreciate the efforts for sample collection performed by Abdullah Al-Afief.

Conflicts of Interest: Authors declare no conflict of interest.

\section{References}

1. Ryan, U.; Fayer, R.; Xiao, L. Cryptosporidium species in humans and animals: Current understanding and research needs. Parasitology 2014, 141, 1667-1685. [CrossRef] [PubMed]

2. Parghi, E.; Dash, L.; Shastri, J. Evaluation of different modifications of acid-fast staining techniques and stool enzyme-linked immunosorbent assay in detecting fecal Cryptosporidium in diarrheic HIV seropositive and seronegative patients. Trop. Parasitol. 2014, 4, 99-104. [PubMed]

3. Wang, Z.D.; Liu, Q.; Liu, H.H.; Li, S.; Zhang, L.; Zhao, Y.K.; Zhu, X.Q. Prevalence of Cryptosporidium, microsporidia and Isospora infection in HIV-infected people: A global systematic review and meta-analysis. Parasit. Vectors 2018, 11, 28. [CrossRef] [PubMed]

4. Checkley, W.; White, A.C., Jr.; Jaganath, D.; Arrowood, M.J.; Chalmers, R.M.; Chen, X.M.; Fayer, R.; Griffiths, J.K.; Guerrant, R.L.; Hedstrom, L.; et al. A review of the global burden, novel diagnostics, therapeutics, and vaccine targets for cryptosporidium. Lancet Infect. Dis. 2015, 15, 85-94. [CrossRef]

5. Besser-Wiek, J.W.; Forfang, J.; Hedberg, C.W.; Korlath, J.A.; Osterholm, M.T.; Sterling, C.R. Foodborne outbreak of diarrheal illness associated with Cryptosporidium parvum - Minnesota, 1995. J. Am. Med Assoc. 1996, 276, 1214.

6. $\quad$ Addiss, D.G.; Pond, R.S.; Remshak, M.; Juranek, D.D.; Stokes, S.; Davis, J.P. Reduction of risk of watery diarrhea with point-of-use water filters during a massive outbreak of waterborne Cryptosporidium infection in Milwaukee, Wisconsin, 1993. Am. J. Trop. Med. Hyg. 1996, 54, 549-553. [CrossRef] [PubMed]

7. Centers for Disease Control and Prevention. Outbreaks of pseudo-infection with Cyclospora and Cryptosporidium-Florida and New York City, 1995. Morb. Mortal. Wkly. Rep. 1997, 46, 354.

8. Pielok, L.; Nowak, S.; Kludkowska, M.; Frackowiak, K.; Kuszel, L.; Zmora, P.; Stefaniak, J. Massive Cryptosporidium infections and chronic diarrhea in HIV-negative patients. Parasitol. Res. 2019, 118, 1937-1942. [CrossRef]

9. Daniels, M.E.; Smith, W.A.; Jenkins, M.W. Estimating Cryptosporidium and Giardia disease burdens for children drinking untreated groundwater in a rural population in India. PLoS Negl. Trop. Dis. 2018, 12. [CrossRef]

10. Hijjawi, N.; Zahedi, A.; Kazaleh, M.; Ryan, U. Prevalence of Cryptosporidium species and subtypes in paediatric oncology and non-oncology patients with diarrhoea in Jordan. Infect. Genet. Evol. 2017, 55, 127-130. [CrossRef] 
11. Mohaghegh, M.A.; Hejazi, S.H.; Ghomashlooyan, M.; Kalani, H.; Mirzaei, F.; Azami, M. Prevalence and clinical features of Cryptosporidium infection in hemodialysis patients. Gastroenterol. Hepatol. Bed Bench 2017, 10, 137-142. [PubMed]

12. Mahgoub, E.; Al Mahbashi, A.; Abdul Latif, B. Cryptosporidiosis in children in a north Jordanian paediatric hospital. East Mediterr. Health J. 2004, 10, 494-501. [PubMed]

13. Sannella, A.R.; Suputtamongkol, Y.; Wongsawat, E.; Caccio, S.M. A retrospective molecular study of Cryptosporidium species and genotypes in HIV-infected patients from Thailand. Parasit. Vectors 2019, 12, 91. [CrossRef] [PubMed]

14. Limaheluw, J.; Medema, G.; Hofstra, N. An exploration of the disease burden due to Cryptosporidium in consumed surface water for sub-Saharan Africa. Int. J. Hyg. Environ. Health 2019, 222, 856-863. [CrossRef] [PubMed]

15. Lal, A.; Fearnley, E.; Wilford, E. Local weather, flooding history and childhood diarrhoea caused by the parasite Cryptosporidium spp.: A systematic review and meta-analysis. Sci. Total Environ. 2019, 674, 300-306. [CrossRef]

16. Khan, A.; Shams, S.; Khan, S.; Khan, M.I.; Khan, S.; Ali, A. Evaluation of prevalence and risk factors associated with Cryptosporidium infection in a rural population of district Buner, Pakistan. PLoS ONE 2019, 14. [CrossRef]

17. Vermeulen, L.C.; van Hengel, M.; Kroeze, C.; Medema, G.; Spanier, J.E.; van Vliet, M.T.H.; Hofstra, N. Cryptosporidium concentrations in rivers worldwide. Water Res. 2019, 149, 202-214. [CrossRef]

18. Stokdyk, J.P.; Spencer, S.K.; Walsh, J.F.; de Lambert, J.R.; Firnstahl, A.D.; Anderson, A.C.; Rezania, L.W.; Borchardt, M.A. Cryptosporidium Incidence and Surface Water Influence of Groundwater Supplying Public Water Systems in Minnesota, USA. Environ. Sci. Technol. 2019, 53, 3391-3398. [CrossRef]

19. Masina, S.; Shirley, J.; Allen, J.; Sargeant, J.M.; Guy, R.A.; Wallis, P.M.; Scott Weese, J.; Cunsolo, A.; Bunce, A.; Harper, S.L. Weather, environmental conditions, and waterborne Giardia and Cryptosporidium in Iqaluit, Nunavut. J. Water Health 2019, 17, 84-97. [CrossRef]

20. Zhao, W.; Zhou, H.; Jin, H.; Liu, M.; Qiu, M.; Li, L.; Yin, F.; Chan, J.F.; Lu, G. Molecular prevalence and subtyping of Cryptosporidium hominis among captive long-tailed macaques (Macaca fascicularis) and rhesus macaques (Macaca mulatta) from Hainan Island, southern China. Parasit. Vectors 2019, 12, 192. [CrossRef]

21. Tan, T.K.; Low, V.L.; Ng, W.H.; Ibrahim, J.; Wang, D.; Tan, C.H.; Chellappan, S.; Lim, Y.A.L. Occurrence of zoonotic Cryptosporidium and Giardia duodenalis species/genotypes in urban rodents. Parasitol. Int. 2019, 69, 110-113. [CrossRef] [PubMed]

22. Abo-Shehada, M.; Hindyia, M.; Saiah, A. Prevalence of Cryptosporidium parvum in private drinking water cisterns in Bani-Kenanah district, northern Jordan. Int. J. Environ. Health Res. 2004, 14, 351-358. [CrossRef] [PubMed]

23. Hijjawi, N.; Mukbel, R.; Yang, R.; Ryan, U. Genetic characterization of Cryptosporidium in animal and human isolates from Jordan. Vet. Parasitol. 2016, 228, 116-120. [CrossRef] [PubMed]

24. Nimri, L.F.; Hijazi, S.S. Cryptosporidium. A cause of gastroenteritis in preschool children in Jordan. J. Clin. Gastroenterol. 1994, 19, 288-291. [CrossRef] [PubMed]

25. Nimri, L.F.; Batchoun, R. Prevalence of Cryptosporidium species in elementary school children. J. Clin. Microbiol. 1994, 32, 1040-1042.

26. El-Kady, A.M.; Fahmi, Y.; Tolba, M.; Hashim, A.A.; Hassan, A.A. Cryptosporidium infection in chronic kidney disease patients undergoing hemodialysis in Egypt. J. Parasit. Dis. 2018, 42, 630-635. [CrossRef]

27. Tonelli, M.; Wiebe, N.; Culleton, B.; House, A.; Rabbat, C.; Fok, M.; McAlister, F.; Garg, A.X. Chronic kidney disease and mortality risk: A systematic review. J. Am. Soc. Nephrol. 2006, 17, 2034-2047. [CrossRef]

28. Karadag, G.; Tamer, G.S.; Dervisoglu, E. Investigation of intestinal parasites in dialysis patients. Saudi. Med. J. 2013, 34, 714-718.

29. Kulik, R.A.; Falavigna, D.L.M.; Nishi, L.; Araujo, S.M. Blastocystis sp. and other intestinal parasites in hemodialysis patients. Braz. J. Infect. Dis. 2008, 12, 338-341. [CrossRef]

30. Omrani, V.F.; Fallahi, S.; Rostami, A.; Siyadatpanah, A.; Barzgarpour, G.; Mehravar, S.; Memari, F.; Hajialiani, F.; Joneidi, Z. Prevalence of intestinal parasite infections and associated clinical symptoms among patients with end-stage renal disease undergoing hemodialysis. Infection 2015, 43, 537-544. [CrossRef]

31. Seyrafian, S.; Pestehchian, N.; Kerdegari, M.; Yousefi, H.A.; Bastani, B. Prevalence rate of Cryptosporidium infection in hemodialysis patients in Iran. Hemodial. Int. 2006, 10, 375-379. [CrossRef] [PubMed] 
32. Chieffi, P.P.; Sens, Y.A.; Paschoalotti, M.A.; Miorin, L.A.; Silva, H.G.; Jabur, P. Infection by Cryptosporidium parvum in renal patients submitted to renal transplant or hemodialysis. Rev. Soc. Bras. Med. Trop. 1998, 31, 333-337. [CrossRef] [PubMed]

33. Nimri, L.F. Cyclospora cayetanensis and other intestinal parasites associated with diarrhea in a rural area of Jordan. Int. Microbiol. 2003, 6, 131-135. [CrossRef] [PubMed]

34. Hijjawi, N.; Ng, J.; Yang, R.; Atoum, M.F.; Ryan, U. Identification of rare and novel Cryptosporidium GP60 subtypes in human isolates from Jordan. Exp. Parasitol. 2010, 125, 161-164. [CrossRef]

35. Batieha, A.; Abdallah, S.; Maghaireh, M.; Awad, Z.; Al Akash, N.; Batieneh, A.; Ajlouni, K. Epidemiology and cost of haemodialysis in Jordan. East Mediterr. Health J. 2007, 13, 654-663.

36. Turkcapar, N.; Kutlay, S.; Nergizoglu, G.; Atli, T.; Duman, N. Prevalence of Cryptosporidium infection in hemodialysis patients. Nephron 2002, 90,344-346. [CrossRef]

37. Hazrati Tappeh, K.; Gharavi, M.; Makhdoomi, K.; Rahbar, M.; Taghizadeh Afshari, A. Prevalence of Cryptosporidium spp. infection in renal transplant and hemodialysis patients. Iran. J. Public. Health. 2006, 35, 54-57.

(C) 2019 by the authors. Licensee MDPI, Basel, Switzerland. This article is an open access article distributed under the terms and conditions of the Creative Commons Attribution (CC BY) license (http://creativecommons.org/licenses/by/4.0/). 